\title{
Responding to the establishment of new pests and diseases: What can be learnt from tomato potato psyllid and Candidatus Liberibacter solanacearum in New Zealand?
}

\author{
D.A.J. Teulon ${ }^{1,2}$ and M.G. Hill ${ }^{1}$ \\ ${ }^{1}$ The New Zealand Institute for Plant \& Food Research Limited, Private Bag 4704, \\ Christchurch 8140, New Zealand \\ ${ }^{2}$ Better Border Biosecurity (B3), New Zealand (http://b3nz.org) \\ Corresponding author:david.teulon@plantandfood.co.nz
}

\begin{abstract}
The response to the incursion of tomato potato psyllid (TPP), Bactericera cockerelli (Šulc) (Hemiptera: Triozidae) and the pathogen Candidatus Liberibacter solanacearum (CLso), first recorded in New Zealand in 2006 and 2008, respectively, has been well documented. However, development of a bioprotection research programme to underpin effective crop production in the presence of TPP/CLso has not. This paper examines the strategic and operational responses of the main Crown Research Institute involved, in parallel with industry actions, in terms of the co-ordination, prioritisation and implementation of a proportionally increasing research programme, after it became clear that eradication of these organisms was not feasible. The establishment of TPP/CLso in New Zealand underlines the fragility of current integrated pest management (IPM) systems and the challenges faced by small industries to the establishment of poorly understood organisms with complex pest/disease/host plant interactions whose impacts were not immediately obvious. Insights are provided into how a research response to similar establishments might be developed in the future.
\end{abstract}

Keywords Bactericera cockerelli, Zebra chip, bioprotection response, research implementation.

\section{INTRODUCTION}

New Zealand agro-ecosystems are dominated by pests and diseases that have mostly originated from elsewhere. New species continue to threaten New Zealand, with some successfully establishing each year (Goldson et al. 2015). Amongst these are species that have negative impacts on New Zealand's productive sectors and natural ecosystems and add to ongoing and increasing pest and disease burdens. Historically, the initial response to the finding of a new species (i.e. up until the species has established populations that cannot be eradicated) has been managed by the Ministry for Primary Industries (MPI) (formerly the Ministry of Agriculture and Forestry (MAF)). This initial response is closely managed by MPI and follows principles and protocols outlined in the Biosecurity Response Knowledge Base (MPI 2012). In future, many such responses will probably be jointly managed by MPI and industry interests through the Government Industry Agreement (GIA) for Readiness and Response (GIA 2015). In most cases, once a 
species is considered to have established (or to be ineradicable), MPI's interests in ongoing 'pest management' decrease and it becomes a primary concern of the industries affected by that species to manage it.

Development of effective management systems for recently established pests and diseases will require some degree of research, as even those species that are well known in other countries are unlikely to behave in exactly the same way under New Zealand conditions (Goldson et al. 2015). Where there is little information on the pests and diseases in their areas of origin, the research challenges for New Zealand become daunting. In many instances it is this first phase of pest or disease establishment that leads to confusing and often suboptimal (sometimes inappropriate) approaches to management, as well as significant economic damage, including loss of markets. In all but the most simple of cases, common sense would indicate that strategic alliances between research providers and industry would enable the most effective pest management outcomes.

The tomato potato psyllid (TPP), Bactericera cockerelli (Šulc) (Hemiptera: Triozidae), and the plant pathogen it transmits, Candidatus Liberibacter solanacearum (CLso), were first recorded in New Zealand in 2006 and 2008, respectively. The immediate response to the incursion of these organisms has been well documented (Teulon et al. 2009; Thomas et al. 2011), but as is the case with the intial responses to the establishment of many other pests and diseases, the development of bioprotection research and extension programmes required to maintain crop protection has not.

The combined impact of TPP and CLso was the most significant new pest and disease incursion for the vegetable sector in New Zealand in the last 20 years. Establishment of Western flower thrips in 1992 (Martin \& Workman 1994), Intonsa flower thrips in 2002 (Teulon \& Nielsen 2005), lettuce aphid in 2002 (Stufkens \& Teulon 2003) and sweet potato whitefly Q in 2006 (Scott et al. 2007) were either managed without significant changes to current practices, were limited in the crops they attacked and/or had relatively minor economic impacts. With TPP/CLso, IPM systems in a range of solanaceous crops were destroyed, hundreds of millions of dollars in crop losses, yield reduction and quality issues resulted, crop management costs increased, and market closures and restriction resulted (Ogden 2011). Indeed the poorly understood and complex TPP/CLso/hostplant interactions would have been a challenge to any industry. The establishment of TPP and CLso presented the respective vegetable and fruit industries and their science providers with significant challenges, and therefore provides a valuable case study for examining what went well, what did not, and how research providers and their industry partners can develop research programmes to respond to future establishments of significant pests and diseases.

This paper reviews the actions of the organisation undertaking the main research on TPP and CLso (Crop \& Food Research (CFR) at the time of the incursion, but later The New Zealand Institute for Plant \& Food Research Limited (PFR)). This institute worked in parallel with industry, to co-ordinate, prioritise, identify funding sources and implement a research programme to underpin the ongoing management of the TPP/CLso complex in a range of solanaceous crops, after it became clear that eradication was not feasible. While focussing on $\mathrm{CFR} / \mathrm{PFR}$, it is recognised that other organisations and industries have invested resources in valuable TPP/CLso research. However, CFR/PFR provided by far the largest research investment in this area (Ogden 2011). The aim of this review is to identify weaknesses and strengths of this response that can inform future responses for other newly established pests and diseases, with resulting improved pest management outcomes. Excluded from the review are the appropriateness of the decisions made on research priorities, the effectiveness of the research outputs and outcomes, and the relative merits of any alternative response strategies.

\section{METHODS}

The following process was followed to inform this review. Terms of Reference for canvassing opinions were developed in January 2012 (D.A.J. 
Teulon, unpublished data). The Terms of Reference focused on the activities of CFR and later PFR, and included a range of questions relating to the situation before, during and after TPP/CLso establishment, and focused on the co-ordination, prioritisation, funding and implementation of research to underpin ongoing management of TPP/CLso. Twenty-two people involved in the incursion from MPI, CFR/PFR, and industry (see Acknowledgements) were interviewed between January 2012 and June 2012. Key messages on the major issues that impacted the response were collated, summarised and interpreted to provide recommendations for future incursions. Individual and isolated opinions are not presented or discussed. Findings were discussed and draft conclusions were critiqued by key PFR personnel (see Acknowledgements), during three presentations held in Auckland (PFR), Wellington (B3 Science Partnership Forum) and Christchurch (PFR) and through internal PFR review of the manuscript (in total $>50$ people participated in these activities). Timelines for the key events (e.g. spread and impact) during the incursions and establishment were developed from these and other sources (e.g. Teulon et al. 2009; Ogden 2011). The outcomes from these activities provide the basis for the interpretations presented here. The basis for the discussion and conclusions below are inherently selective and therefore subjective, but the robust iterative review process from informed actors prior to publication provided a check on the authenticity of this approach and the conclusions reached.

\section{RESULTS AND DISCUSSION}

\section{Spread and impact}

The initial spread and impact of TPP and CLso in New Zealand was detailed by Teulon et al. (2009), and Ogden (2011) provided a useful analysis of their economic impact. TPP and CLso were first recorded in New Zealand in 2006 and 2008, respectively, but were considered most likely to have arrived together in 2005 (Table 1). By April 2009 both had spread throughout much of New Zealand. The focus of the New Zealand greenhouse industry is around Auckland City, which was also the focal point for the first TPP confirmed occurrences. The impact of TPP was first apparent in the greenhouse industry in 2006-07, where increased use of non-selective chemicals for TPP control began jeopardising well-established IPM programmes. Major problems with TPP were subsequently noticed in outdoor tomatoes in Hawke's Bay, with severe yield effects in 2007-08. New insecticide programmes in outdoor tomato production systems were then implemented, which also disrupted the IPM programmes in these crops. In potatoes, impacts of TPP and CLso were apparent as early as 2007-08 in CFR plant breeding trials at Pukekohe. In the 2008-09 season, TPP/CLso symptoms in commercial processing potatoes became common in some North Island crops. Zebra chip symptoms, which are generally regarded as being caused by CLso, did not become apparent in produce from South Island potato crops until the 2013/14 season (Vereijssen et al. 2015). Up until the end of the 2010-11 season, Ogden (2011) estimated that TPP and CLso had cost the potato industry at least $\$ 120$ million. The tamarillo industry was also badly affected, with many growers leaving the industry (Ogden 2011).

\section{Research response}

In mid 2006, strategic initiatives were underway to strengthen the research capability for the greenhouse crops sector in New Zealand with a Horticulture New Zealand (Hort NZ) (Fresh Vegetable \& Fresh Tomato Product Groups) led MAF Sustainable Farming Fund (SFF) project, and a CFR internally-funded research initiative. As the seriousness of TPP became more apparent after mid-2006, the research priorities for both of these projects were reprioritised towards TPP. Similarly, some research within two Government funded programmes - 'Future Vegetables' and 'Sustainable IPM' - were reprioritised towards TPP research. From 2009 onwards, PFR made a considerable and ongoing investment in TPP/CLso research through its internal discretionary Core funding. This provided an effective, sizable and flexible investment, which increased proportionally 
over time as the impact of the new pests became more apparent. Investment in TPP/CLso research continues to be high priority for PFR. According to Ogden (2011), PFR was by far the largest research investor in TPP/CLso research. At the same time, PFR leveraged other funding through a Horticulture Australia Limited (Australian Potato Research Program Phase 2 (APRP2)) investment. A new SFF project, focusing on TPP/ CLso management in a range of solanaceous crops, began in 2009, followed by a third SFF focusing solely on potatoes in 2011. More recently, a sizable research programme has been funded through the Ministry for Business, Innovation and Employment (MBIE 2015) and several projects have been funded through the Plant Biosecurity CRC (e.g. PBCRC 2014). Various industry sectors, especially the processing tomato and covered crops, initiated their own research projects.

The short-term goal of these research initiatives was to enable growers to control psyllids to manageable numbers and to produce economically viable crops. These immediate management approaches were not necessarily in the context of IPM programmes, so would not necessarily be considered best practice in the medium/longer term, but were critical to protect the viability of the industries. Medium-term aims were to develop ways to use insecticides more effectively/sustainably and to integrate their use with other control measures, such as oils, coatings and repellents, and to enhance natural enemy populations. Other research priorities included investigating the factors affecting transmission of CLso (including potato tuber transmission), the role of non-crop hosts in the environment, population modelling of TPP, options for classical biological control, and improved diagnostic methods for CLso (see Ogden 2011).

\section{Research management - coordination and leadership}

The initial research focus on TPP was through the Hort NZ/MAF SFF (Leader: Vegetable Research and Innovation Manager) and CFR internal project (Co-leaders: Entomology \& Plant Pathology Team Leaders), but both projects were focused on greenhouse crops. Initially, leadership for all TPP research was through these projects and largely co-ordinated through regular meetings of the Hort NZ/MAF SFF Project Team, which included a wide range of industry interests. Although the processing tomato sector carried out most of its own research independently, they also attended the MAF SFF Project Team meetings. As the negative impacts of TPP became more apparent, and especially with the discovery of CLso and the withdrawal of export certification for tomatoes and capsicums, CFR appointed a Science Team Leader in June 2008 to provide a single point of contact on all TPP/CLso issues and give clear and consistent communication to all parties. CFR merged with HortResearch to become PFR in December 2008.

In response to the growing awareness of the impact of TPP/CLso on potatoes, Potatoes NZ appointed a Psyllid Co-ordinator in early 2010. In consultation with PFR, the Psyllid Co-ordinator developed a Research Road Map, completed in mid 2010. The road map consolidated research projects and timelines, identified research gaps and funding needs, and aligned industry needs with research priorities (Psyllid News 2010). The position was discontinued in 2013. Potatoes NZ also developed an extension programme that included regional discussion groups, annual psyllid updates from New Zealand scientists, visits from US experts, and the production of "Psyllid News". This newsletter summarised New Zealand and international research developments, provided regular updates to the industry, and attempted to link the grower and scientific communities (Ogden 2011).

In late 2010, PFR also appointed a senior science leader as the PFR Psyllid Co-ordinator, in recognition of the ongoing focus required to respond to the newly established pest and associated disease.

\section{Risk assessment}

Probably the greatest challenge in developing an effective research programme in response to the establishment of this new pest and disease was the lack of understanding of the pest status 
Table 1 Timeline for significant events (2005-2010) for the establishment of the tomato potato psyllid (TPP) and Candidatus Liberibacter solanacearum (CLso) in New Zealand. Information from Teulon et al. (2009) and Ogden (2011).

March 2006: First authenticated record of TPP from tomato in Clevedon, Auckland (but only recognised in May)

May 2006: TPP discovered in Kumeu tomato glasshouse and Taupo capsicum greenhouse

May 2006: Delimiting survey establishes TPP in several locations in Auckland city

June 2006: Outdoor population in Pukekohe, South Auckland, discovered

June 2006: MAFBNZ decides not to attempt eradication of TPP

July 2006: CFR internal Covered Crops project started

January 2007: Horticulture NZ Covered Crops MPI/SFF project started

June 2007: InsectWatch.com website initiated

June 2007: TPP found in Nelson tomato greenhouse

January 2008: TPP in Hawke's Bay

February 2008: TPP in Canterbury, Wellington and Gisborne

April 2008: CLso discovery confirmed from capsicum greenhouse in Auckland

May 2008: Pukekohe potatoes with Zebra-chip test positive for CLso

June 2008: MAFBNZ briefly withdraws its phytosanitary certification for export of capsicums and tomatoes (reinstated July 2008)

June 2008: CFR appoints Science Team Leader as single point of contact with MAF and industry

July 2008: MAFBNZ survey of solanaceous plant species confirmed presence of CLso in both the North and South Islands

July 2008: Brainstorm Session on research required on Liberibacter with MAFBNZ, CFR and industry July 2008: CFR laboratory gains accreditation from MAF for Liberibacter testing

November 2008: Interim insecticide resistance management strategy published

December 2008: CRF merges with HortResearch to become PFR

Late 2008: CLso detected in most tamarillo growing areas

January 2009: Horticulture Australia Ltd TPP project started

July 2009: TPP SFF project started

Early 2010: Potatoes NZ appoints Psyllid Coordinator

May 2010: PFR Science Potato Review

May 2010: PFR Tomato Potato Psyllid/Liberibacter/Phytoplasma Working Group convened

Mid 2010: TPP/CLso potato research roadmap completed

December 2010: PFR TPP Programme Co-ordinator appointed

and the economic impacts of TPP and especially CLso. Prior to 2006, TPP was known to be a pest in North and Central America (Wallis 1955; Secor \& Rivera-Varas 2004; Munyaneza 2009), but one that could be adequately managed with insecticides. In 2006, before it was found in New Zealand, TPP was listed as a biosecurity threat in a draft pictorial guide for field workers of invasive diseases and pests of New Zealand tomatoes (reported in Martin et al. 2009), but its potential importance had not then become realised by the wider industry. It was not part of any formal pest risk assessment carried out by MPI. Thus, there was very low awareness of this insect in New Zealand prior to its first report in May 2006 (Thomas et al. 2011). 
Only after TPP had become widespread in New Zealand in 2008 and CLso became known to science (Hansen et al. 2008; Liefting et al. 2008), did the true pest status of TPP as a vector of CLso in a range of solanaceous crops become understood (Teulon et al. 2009). An accurate risk assessment of TPP and CLso in 2006 was therefore not possible, so could not provide a useful basis for an effective research programme to develop a long-term management scheme. Additionally, the results and conclusions from studies in the Central and North America have been of limited value for understanding and responding to the New Zealand establishment. This is due to different vectorpathogen parameters (including genotypes), the effects of the New Zealand environment (climate and host plants), potato crop management, the effect of potato genotypes on disease epidemiology, and differing approved pest management tools, particularly approved insecticides. The main sectors affected by TPP/CLso, in particular the field potato sector, initially underestimated the seriousness of the situation. It was not until the full impact of CLso became apparent in 2009 that some industries began to take it seriously.

\section{Mobilisation of resources and co-ordination of research}

In hindsight, and taking into account the limited prior knowledge of TPP/CLso risk and the lack of a recent high impact incursion in the vegetable industry (see above), MPI, CFR/PFR and industry could have been better prepared for TPP/CLso. In 2006, CFR/PFR had no policy for assessing the risk for new pest or disease incursions, no systematic way of listing potential risks, and no plan for responding to incursions or allocating or re-allocating resources for dealing with new incursions, including those that could not be eradicated and so required long-term management. Neither did the vegetable industries. The relative fragmentation of the industries affected (fresh vegetables - capsicums, fresh tomatoes, processing tomatoes, seed potatoes, processed potatoes, fresh potatoes and tamarillos) compounded the challenge of mounting a cohesive and coordinated response. Nevertheless, the initial research projects were highly collaborative and there was a proportional increase in research investment from a variety of funding sources as the impacts of TPP/CLso were realised. The use of PFR Core funding was particularly valuable as it could be quickly mobilised through internal reprioritisation, and provided resource levels of size to develop effective research projects targeting strategic outcomes.

Initially, research leadership was projectbased, with significant overlap of personnel across different projects but with limited coordination across research groups. As the incursion intensified and greater resources were utilised, a CFR/PFR Science Team Leader was appointed as the coordinator/contact for TPP/CLso research in 2008. However, the main interactions between CFR/PFR and industry were still carried out at the scientist/business leader level, with modest senior management, administrative or communications support. At this time, some scientists considered their positions to be exposed, inadequately supported and stressful because of constant industry demands for information and advice at a time when research results were very preliminary. Experience with other sectors confirms that the establishment of new pests or diseases puts extreme pressure on the research community as the industry seeks answers to questions that have not been previously or adequately examined. One industry manager suggested that CFR/PFR needed an extension person to communicate with industry, believing that scientists do not always do extension well, and should not be constantly distracted by having communicate with industry. However, they too would have been constrained by lack of information to support management advice for growers. This view of scientists may not be limited to bioprotection responses. There was consistently held opinion from CFR/ PFR science staff and industry leaders that the CFR/HortResearch merger in late 2008 created a discontinuity in strategy, operations and resource allocation to the response, as some staff left their positions and others needed to 'come up to speed' with their new responsibilities. 
As the full impact of TPP/CLso became apparent in 2009, and as research investment was increasing, industry and PFR senior managers became increasingly involved. The PFR TPP Working Group, formed in May 2010, included a PFR Science General Manager and provided a significant improvement in support to scientists, broadening the risks across PFR, improving co-ordination and internal communication, and creating focus. However, some felt that this development created an administrative layer between scientists and industry leaders that was perceived to impede direct communication. In spite of these issues, overall CFR/PFR researchers and management maintained good relations with industry and were highly regarded by them.

The appointment of the Potatoes NZ Psyllid Co-ordinator in early 2010 was considered by many to be a turning point in the strategic response to the TPP/CLso outbreak. In response to recommendations from an internal Potato Science Review of its whole potato research investment, PFR appointed a senior scientist as an internal TPP/CLso co-ordinator in late 2010, to work alongside the industry co-ordinator. This role was welcomed by researchers and industry. In late 2010, the arrival of Pseudomonas syringae pv. actinidiae (Psa) in New Zealand (Vanneste 2012) put further pressure on PFR's bioprotection resources.

\section{Future pest and disease establishments}

New Zealand is at risk from a range of new pests and pathogens. In many cases these organisms will be intercepted at the border, and in others they will be eradicated before they establish (Kriticos et al. 2005). Unfortunately, in some cases pests or pathogens will establish and add to the management burden of the crops they attack (Goldson et al. 2015). It is important that the New Zealand bioprotection community learns from previous responses to the establishment of new pests or diseases, in order to minimise the impacts they are likely to have on our crop management systems in the future.

The research response to the establishment of TPP and CLso in New Zealand has highlighted five areas of critical importance. These are (1) the fragility of current IPM systems in the face of new pest and/or pathogen incursions, (2) the need for effective intelligence (risk assessment) and sharing of this between agencies on species likely to establish and their likely impact, in order to direct research activity towards them, and create understanding of their biology and likely impacts in New Zealand, (3) high-level leadership that enables the rapid, timely and effective response to pest or disease establishments, including appointment of key staff and support teams, negotiation of strategic partnerships, allocation of resources (personnel, financial, equipment) including administrative and communications support, and providing a 'license to operate', (4) effective communication and partnerships (co-ordination) between research providers and industry and (5) development of operational plans that consolidate research projects and timelines, identify research gaps and funding needs, align research priorities with industry needs and provide effective extension knowledge to growers.

The Government Industry Agreement (GIA) for Readiness and Response, which has been promulgated under the Biosecurity Law Reform Bill (September 2012), aims to facilitate joint planning and response activities between government and industries to deal with future biosecurity incursions, as industries agree to join (GIA 2015). A major challenge for the research response to the establishment of new organisms such as TPP/ CLso that attack a range of crops is the number of industry entities that could be involved in such a response. Furthermore, the role of research providers in GIAs is currently unclear.

\section{SUMMARY}

Neither MPI, CFR/PFR nor the industries affected were prepared for the consequences of the establishment of TPP/CLso in New Zealand. Despite TPP's pest status in Central and North America, it was not widely recognised as a threat for New Zealand crops. Furthermore, CLso was unknown to science before it arrived in New Zealand, so the consequences of its establishment could not have been foreseen. There was a 
gradual increase of evident impact over time as TPP/CLso spread throughout New Zealand and through different cropping systems (covered crops, tamarillos, outdoor tomatoes, potatoes), which was not well forecasted within CFR/PFR or industry. Consequently, the response by CFR/ PFR, industry and government, in leadership, co-ordination and research investment (from a variety of sources), grew over time. Once the significance of the incursion became evident in 2008-09, the resulting pressure imposed on TPP/CLso researchers as a result of industry expectations to provide short-term solutions became intense. Nevertheless, the relationships between industry leaders and CFR/PFR scientists and managers were generally positive, with industry respecting the research effort and expertise. CRI Core funding provided an effective, sizeable and flexible investment, which increased over time as the impact of the incursion became more apparent. As in most other areas of scientific endeavour, CFR/PFR had to prioritise research projects/programmes with respect to TPP/CLso, sometimes with limited information. The PFR Potato Science Review's two main recommendations (appoint a TPP/ CLso co-ordinator and increase investment) made significant improvements to PFR's TPP/ CLso research response. Any new establishment of a major pest or disease to a New Zealand productive system adds an ongoing burden in the form of lost production and/or increased costs of pest management. Approaches such as the Government Industry Agreement for Readiness and Response will be useful avenues for preparing for and managing new pest and pathogen incursions in the future, once industrygovernment operational agreements are in place and the role of research organisations in the GIA process has been clarified.

\section{ACKNOWLEDGEMENTS}

We thank the following people for being prepared to be interviewed and expressing their opinions: George Gill, Karen Pugh, Karyn Froud (resigned from MPI in 2012), (all MPI), Ron Gall, Stephen Ogden, Sonia Whiteman, Terry Olson (all industry), Andrea Bourhill, Andrew Pitman, Bob Fullerton, Graham Walker, Grant Smith, Ian Scott, Jessica Dohmen-Vereijssen, Lisa Jamieson, Melanie Davidson, Nadine Berry, Peter Cameron, Nicholas Martin, Philippa Stevens, Robin GardnerGee, Warrick Nelson (all PFR). Jessica DohmenVereijssen, Tracy Williams, Grant Smith, Andrew Pitman and Richard Falloon provided useful comments on the manuscript. The work was funded through Plant \& Food Research Core funding aligned to the Better Border Biosecurity (B3) research collaboration (http://b3nz.org) and linked to the Plant Biosecurity CRC project on Pathways and Risk Assessment Framework for High Impact Species (PBCRC1109).

\section{REFERENCES}

GIA 2015. Government Industry Agreement for Readiness and Response. www.gia.org.nz (accessed May 2015).

Goldson SL, Bourdôt GW, Brockerhoff EG, Byrom AE, Clout MN, McGlone MS, Nelson WA, Popay AJ, Suckling DM, Templeton MD 2015. New Zealand pest management: current and future challenges, Journal of the Royal Society of New Zealand DOI: 10.1080/03036758.2014.1000343.

Hansen AK, Trumble JT, Stouthamer R, Paine TD 2008. A new huanglongbing species, "Candidatus Liberibacter psyllaurous," found to infect tomato and potato, is vectored by the psyllid Bactericera cockerelli (Sulc). Applied and Environmental Microbiology 74(18): 5862-5865.

Kriticos DJ, Phillips CB, Suckling DM 2005. Improving border biosecurity: Potential economic benefits to New Zealand. New Zealand Plant Protection 58: 1-6.

Liefting LW, Perez-Egusquiza ZC, Clover GRG, Anderson JAD 2008. A new 'Candidatus Liberibacter' species in Solanum tuberosum in New Zealand. Plant Disease 92(10): 1474.

Martin NA, Workman PJ 1994. Confirmation of pesticide-resistant strain of western flower thrips in New Zealand. Proceedings of the 47th New Zealand Plant Protection Conference: 144-148. 
Martin NA, Wright PJ, Fletcher JD 2009. Unwanted in New Zealand: diseases and pests of crops. In: Froud KJ, Popay AI, Zydenbos SM ed. Surveillance for Biosecurity: PreBorder to Pest Management. New Zealand Plant Protection Society, Hastings, New Zealand. Pp. 81-87.

MBIE 2015. Realising potato export growth through sustainable management of the zebra chip disease complex. Ministry for Business, Innovation and Employment. http://www. msi.govt.nz/update-me/who-got-funded/ show/29 (accessed May 2015).

MPI 2012. Biosecurity Response Knowledge Base.

Ministry for Primary Industries. http//brkb. biosecurity.govt.nz/ (accessed 15 May 2015).

Munyaneza JE, Crosslin JM, Buchman JL 2009. Seasonal occurrence and abundance of the potato psyllid, Bactericera cockerelli, in South Central Washington. American Journal of Potato Research 86: 513-518.

Ogden SC 2011. Tomato potato psyllid and Liberibacter in New Zealand - Impacts and research programme overview. In: Workneh F, Rashed A, Rush CM ed. Proceedings of the 11th Annual Zebra Chip Reporting Session. San Antonio, TX, USA. Pp. 173-177.

PBCRC 2014. Understanding the role of alternative host plants in tomato potato psyllid and Liberibacter life cycle and ecology. Plant Biosecurity Cooperative Research Centre. http://www.pbcrc.com.au/publications/ pbcrc1257 (accessed 15 May 2015).

Psyllid News, July 2010. http://www.potatoesnz. co.nz/users/Image/Downloads/PDFs/ Psyllid_News_July_2010_lowres.pdf (accessed 30 April 2015).

Scott IAW, Workman PJ, Drayton GM, Burnip GM 2007. First record of Bemisia tabaci biotype Q in New Zealand. New Zealand Plant Protection 58: 208-212.
Secor GA, Rivera-Varas VV 2004. Emerging diseases of cultivated potato and their impact on Latin America. Revista Latinoamericana de la Papa (Suplemento) 1: 1-8.

Stufkens MAW, Teulon DAJ 2003. Distribution, host range and flight pattern of the lettuce aphid in New Zealand. New Zealand Plant Protection 56: 27-32.

Teulon DAJ, Nielsen M-C 2005. Distribution of western (glasshouse strain) and Intonsa flower thrips in New Zealand. New Zealand Plant Protection 58: 208-212.

Teulon DAJ, Workman PJ, Thomas KL, Nielsen M.-C 2009. Bactericera cockerelli: Incursion, dispersal and current distribution on vegetable crops in New Zealand. New Zealand Plant Protection 62: 136-144.

Thomas KL, Jones DC, Kumarasinghe LB, Richmond JE, Gill GSC, Bullians MS 2011. Investigation into the entry pathway for tomato potato psyllid Bactericera cockerelli. New Zealand Plant Protection 64: 259-268.

Vanneste JL 2012. Pseudomonas syringae pv. actinidiae (Psa): a threat to the New Zealand and global kiwifruit industry. New Zealand Journal of Crop and Horticultural Science 40 (4): 265-267.

Vereijssen J, Barnes AM, Berry NA, Drayton GM, Fletcher JD, Jacobs JME, Jorgensen N, Nielsen M-C, Pitman AR, Scott IAW, Smith GR, Taylor NM, Teulon DAJ, Thompson SE, Walker MK 2015. The rise and rise of Bactericera cockerelli in potato crops in Canterbury: have lessons been learnt and how does the future look? New Zealand Plant Protection 68: 85-90.

Wallis RL 1955. Ecological studies on the potato psyllid as a pest of potatoes. USDA Technical Bulletin 1107. US Department of Agriculture, Washington, DC, USA. 